\title{
Numerical Investigation of the Impact of Jetties on Accretion Problem at Rosetta Promontory, Egypt
}

\author{
Ali Masria, Abdelazim Negm, Moheb Iskander, and Oliver C. Saavedra
}

\begin{abstract}
Estuaries are very sensitive and vulnerable to any interventions in coastal dynamics. Erosion began to take place since the beginning of the 20th century along Rosetta area, and increased dramatically since the construction of the High Dam in 1964. Many protective works have been implemented and/ or under construction since 1989 and up to the present time. Erosion is not the only problem facing the area but also, the accumulation of sediments inside the inlet is also taking place because of the littoral drift and the absence of the outflow of water from Rosetta branch. This paper aims to reach a new condition of stability of Rosetta Promontory by using boundary jetties to reduce coastal dynamics at the outlet .Moreover the effect of the angle of the western jetty was investigated to reach suitable position of it. This target is achieved by using a hydrodynamic model Coastal Modeling System (CMS). About eight scenarios were tested to reach suitable solutions that mitigate the coastal problems at the inlet specially the accretion problem. The results show that $360 \mathrm{~m}$ jetty combined with an inclined western jetty of $800 \mathrm{~m}$ length enhances the stability of the inlet.
\end{abstract}

Index Terms - Erosion, Rosetta, sedimentation, jetties.

\section{INTRODUCTION}

Inlets play an important role in exchanging water and providing a navigational pathway for ships to travel between the open oceans and sheltered waters [1]. It is a unique environment that connect fresh river water and saline coastal water [2]. In addition, it provides a link between the coastal ocean and back-barrier bay, exchanging water, sediment, nutrients, and other materials between them [3]-[5]. They have a high biological productivity, and are generally situated in densely populated areas [6]. Many different hypotheses have been brought forward to explain inlet closure [7]-[10].

Sedimentation problems generally occur at locations where the sediment transporting capacity of the hydraulic system is reduced due to the decrease of the steady (currents) and oscillatory (waves) flow velocities and related turbulent motions, [11].

Manuscript received March 9, 2014; revised May 15, 2014. The work was supported by Mission Department, Egyptian Ministry of Higher Education (MoHE), Egypt-Japan University of Science and Technology (E-JUST) and partially supported by JSPS "Core-to-Core Program, B.Asia-Africa Science Platforms".

A. Masria, Abdelazim Negm, and Moheb Iskander are with the Environmental Engineering Department, School of Energy and Environmental Engineering, Egypt-Japan University of Science and Technology, Alexandria, Egypt (e-mail: ali.ali@ejust.edu.eg, negm@ejust.edu.eg, coastal_alex@yahoo.com).

O. Saavedra is with the Deptartment of Civil Engineering, Tokyo Institute of Technology, Oookayama, Meguro, Tokyo, Japan, he is also with E-JUST (e-mail: saavedra.o.aa@m.titech.ac.jp).
Engineering modifications at inlets are usually used to enhance navigation process and typically involve a combination of jetties and maintenance of a dredged channel [12]. Although engineering projects are targeted to solve problems, but it can also contribute in creating problems at other nearby locations as an environmental impacts or side effects. It is better to design in a such way that side effects (sand trapping, sand starvation, downdrift erosion) are minimum, [11]. Therefore, understanding of the intervention-induced effects on inlet dynamics, and quantifying its morpho-dynamics is crucial for successful coastal management. Various solutions were performed. For instance, U.S. Army performed a structural solution involving new jetties at the Mouth of the Colorado River (MCR), Texas as the site has experienced excessive sediment shoaling. It is expected that this new jetty will be a permanent structural solution that would reduce dredging frequency while maintaining a reliable channel [13].

However, interaction between controlling structures and hydrodynamics often results in unexpected morphologic changes [14]. The jetties should be long enough such that the sedimentation at the entrance of the channel due to longshore sediments transport is minimum. Sediment accumulation will generally take place on the updrift side of the jetties and erosion on the downdrift side. Mechanical bypassing of sediment may be required to reduce downdrift erosion [11].

In Egypt, the navigation channels, which connect the Mediterranean Sea and the Nile branches, are economically important for thousands of fishers. Rosetta promontory is located on the eastern side of Abu- Quir Bay at about $60 \mathrm{~km}$ to the east of Alexandria city, Egypt as shown in Fig. 1. The promontory suffers from the extensive erosion due to damming the Nile River. Moreover, Rosetta mouth considered as a sink for the eroded sediments transported offshore from Abu Quir Bay and Rosetta [15]. These sediments accumulate inside the inlet and results in a great problems for navigation processes, the living of habitat in this area, and also threaten the nearby areas with inundation in case of flooding conditions as it reduces the capacity of the waterway.

The wide river entrance described probably was responsible for this problem. Fortunately, the problem of sedimentation was solved in 1998. Unexpected high flood waters flushed the lower Nile distributaries including the Rosetta branch [16], but it came back again due the severe reduction in fresh water discharges. In addition, frequent dredging is carried out to overcome the siltation problem inside the estuary, but it failed to solve the siltation problem[15], [17]. This paper focuses on how to stabilize Rosetta promontory by using boundary jetties, and to investigate the best alternative of the western jetty (inclined 
or parallel) in order to reduce the sedimentation at the estuary.

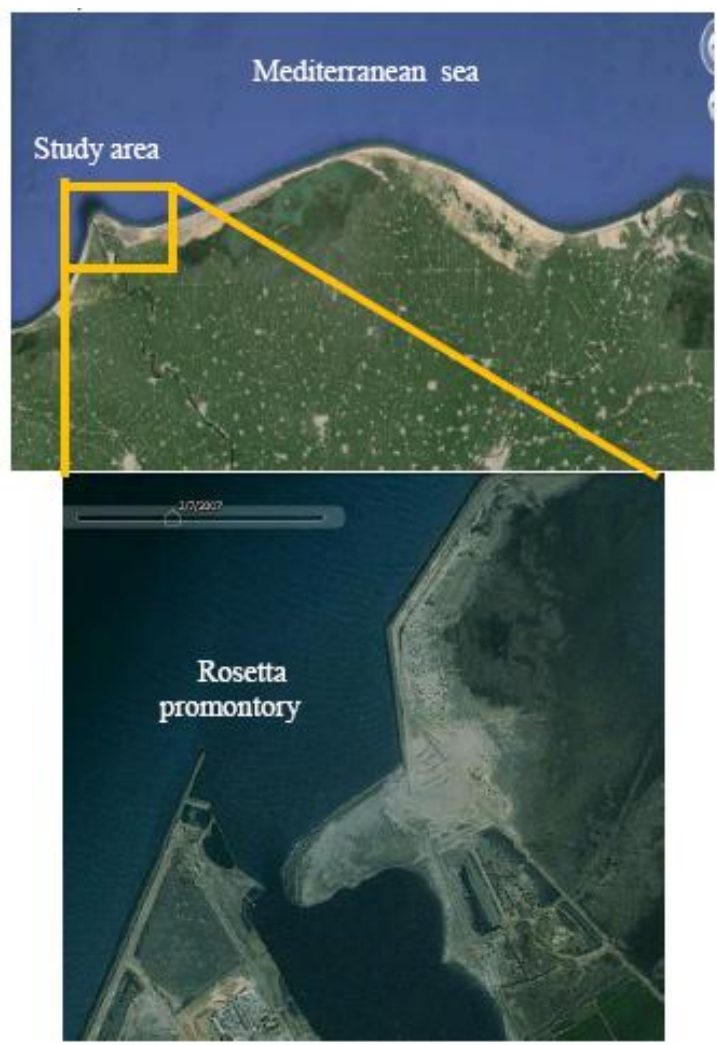

Fig. 1. Location of the study area (Rosetta promontory at the terminal of Rosetta branch, Google earth (2007).

\section{Methodology}

\section{A. Field Data Collection}

The field data (bathymetric, wave, tide, Rosetta branch discharges) was obtained from the Coastal Research Institute, Hydraulic Research Institute (National Water Research Center, Egypt), and Coastal Protection Authority (Ministry of Water Resources and irrigation, Egypt). The bathymetric survey (about 50 profiles which are perpendicular to the coastline) utilized in this study was conducted in October 2005. The bathymetric survey of May 2006 was used to calibrate the numerical model. The wave data are the averaged wave climate of five years between 1986 and 1990. The wave directions are from WNW, NNW, N, and W with a small portion of waves arrived from the NNE and NE especially in March and April [17]. Fig. 2 shows the average wave height- direction distribution where $\mathrm{NW}$ is dominant. The Nile delta coast is a typical micro tidal semi-diurnal tidal regime with a tidal range of $30 \mathrm{~cm} \mathrm{[18].}$

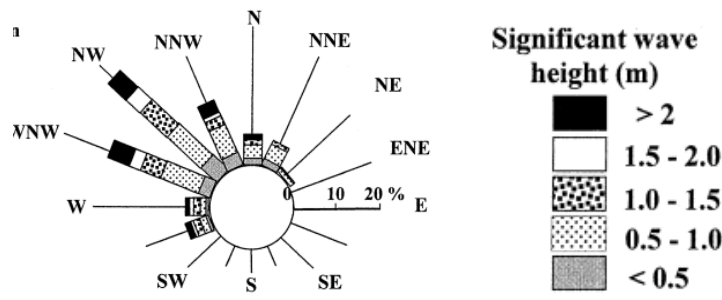

Fig. 2. Average wave direction-height distribution [19].

The available tide data represented in water levels at
Rosetta promontory covered the period from October 2005 to October 2006, Fig. 3. The sediment grain sizes $\left(\mathrm{d}_{50}\right)$ at the nearshore zone of the area of interest are between $0.16 \mathrm{~mm}$ and $0.24 \mathrm{~mm}$ based on previous study [20]. In order to transform the wave from offshore station at depth $18 \mathrm{~m}$ to the model boundary at $11 \mathrm{~m}$ depth, the maximum entropy code (by CMS developers) was applied for the directional spectrum to be ready as input in the model.

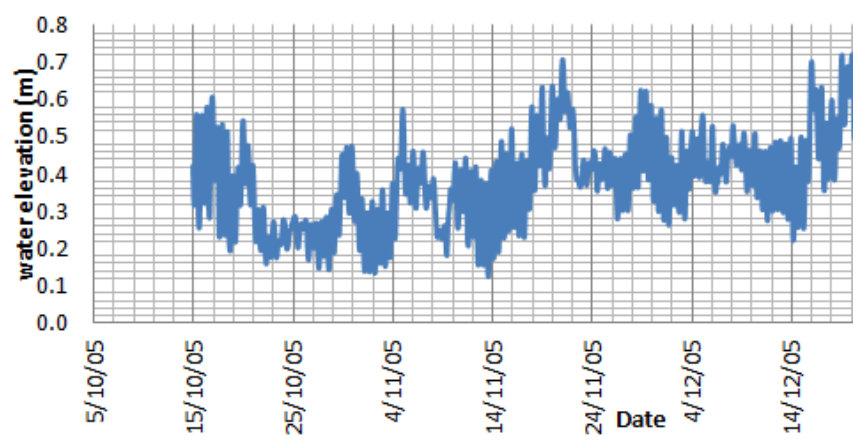

Fig. 3. Sample of measured water levels data by Coastal Research Institute, Egypt (CoRI) 2005.

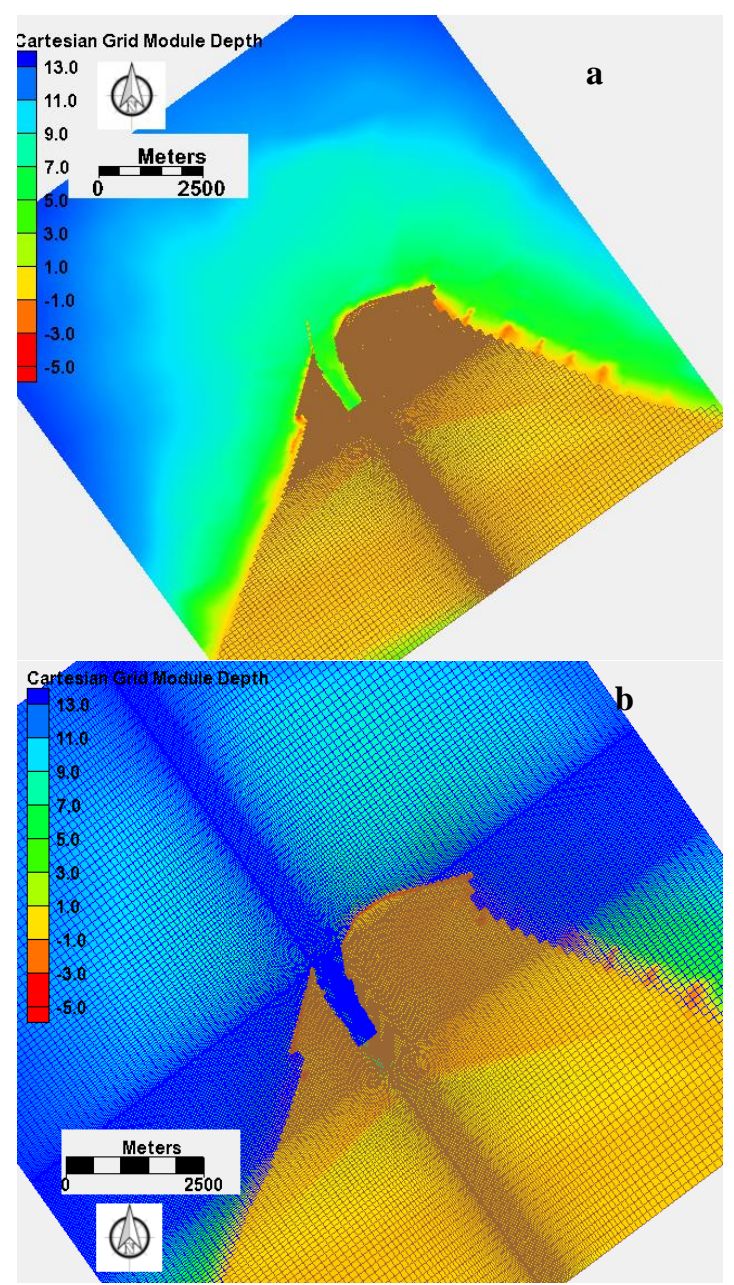

Fig. 4. a) The model domain of Rosetta estuary, depths (positive) are relative to mean sea level, b) The Cartesian grid of the study area.

\section{B. Model Establishment and Calibration}

The near-shore, offshore, the inlet, Rosetta branch, and adjacent beaches were surveyed between 2005 and 2006 by Coastal Research Institute. The CMS grid was constructed based on the above mentioned bathymetric data. A variable 
sized rectangular-cell grid system, with a spatial resolution ranging from $20 \times 20 \mathrm{~m}$ in the vicinity of the inlet, and the near-shore zone, navigation channel to $70 \times 120 \mathrm{~m}$ near the ocean boundary was generated. Having the fine grid spacing at and around the estuary enabled capturing the sediment transport and morphologic change processes where they mainly occurred. Larger the offshore grid spacing, the speeder the computational process is. A CMS-Wave was also generated that had the same dimensions of the flow grid. To simulate the flow field, CMS-Flow was driven by the measured tide along the open boundaries from October 2005 to May 2006. After examining 5 years (1986-1990) records, wave during 1986 was judged to be representative and used in the modeling effort. The half-plane model of CMS-Wave was selected for this study. Fig. 4a, 4b shows the model domain, the CMS grid bathymetry based on the available bathymetric data in October 2005.

The model was calibrated with main focus on the parameter: hydrodynamic time step, Manning coefficient, different transport formulas, scaling factor for bed load and suspended load, total adaptation length, and also the effect of smoothing the bathymetric contour. The correlation coefficient according to bed change and bed depth was calculated at all profiles. The results show that a good agreement with the measurements can be picked up with 0.025 of Manning coefficient, $0.20 \mathrm{~mm}$ of $\mathrm{d}_{50}, 450 \mathrm{sec}$ time step, scaling factor of 2.0 and adaptation length of $10 \mathrm{~m}$. Interested reader can consult [21] for more details on the calibration processes.

\section{RESULTS AND DISCUSSION}

This work is an attempt to reach a new stability condition for the Rosetta promontory. This target can be achieved by controlling the flow and the sediment transport from the eastern and/or western side of the promontory.

This main idea is translated into two groups of coastal structures checked its efficiency by using CMS model. The first group focuses on controlling the sediment transport west of the promontory by using western jetties with different lengths, Table I. This group is proposed as the prevailing wave direction in study area come from WNW, NNW, NW to eliminate the hydrodynamic force west of the estuary.

TABLE I: THE DIFFERENT SCENARIOS OF GROUP 1

\begin{tabular}{cc}
\hline \hline Scenario & Description \\
\hline 1 & An inclined western jetty, (150m long) \\
2 & An inclined western jetty, (300m long) \\
3 & An inclined western jetty, (500m long) \\
4 & An inclined western jetty, (800m long) \\
\hline \hline
\end{tabular}

The second group includes the combination from the most effective scenarios among the first group and eastern jetty, and compare between these scenarios if the western jetty becomes straight not inclined.

Six cross sections inside the Rosetta Inlet were utilized to compare the morphology of bed profiles for the different scenarios as shown in Fig. 5.

In the first group, four scenarios were tested, Table I. Fig. 6 shows the effect of the different lengths of the western jetty on the bed morphology as well as the hydrodynamic parameters at Rosetta promontory after one year. It is clear that accumulated sediments move seaward compared to case of no action. This is due to the existence of the western jetty that shifted the breaking of the waves outside the inlet creating calm conditions behind the jetty as shown in Fig 7a. These conditions reduced the wave induced current inside the inlet which constitute a weak eddy vortex. But, the wave induced-current coming from nodal point at the eastern revetment, still affects the accelerated accumulation of sediments inside the inlet as shown in Fig. 7b. In general, the western jetty is not sufficient alone to solve the promontory problems but can be useful if combined with eastern one.

In the second group, a combination of western jetty of length 500, and $800 \mathrm{~m}$ (inclined and parallel) with an eastern jetty of length $360 \mathrm{~m}$ are checked. The eastern jetty has been used in this group at the eastern tip of the promontory to cut the vortex within this area which has an effect for the sedimentation problem inside the inlet.

The computed bed morphology at the Rosetta inlet after one year from the different scenarios was extracted from model results as shown in Fig. 8.

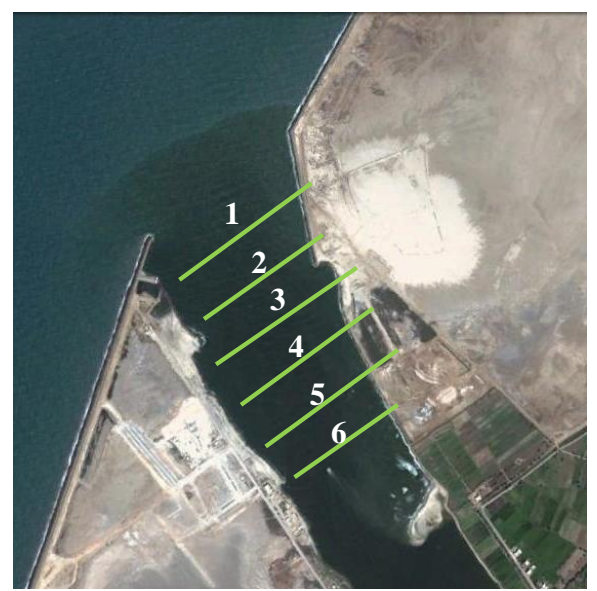

Fig. 5. Cross section through the inlet used in the comparative study of different scenarios.

The results show that, the behavior of the eastern jetty of length $360 \mathrm{~m}$ with inclined western one of length $500 \mathrm{~m}$, and $800 \mathrm{~m}$ is better than the same scenarios with parallel ones. This is due to that, inclined western jetty shifts the wave breaking outside the inlet which creates calm conditions inside the inlet as the wave heights get smaller than those resulted from parallel jetties as shown in Fig. 9a and Fig. 9b. These conditions reduce the wave induced current inside the inlet which constitute a weak eddy vortex.

In addition, the inclined jetties increase the width of the navigation channel as shown in Fig. 9a and Fig. 10. This is due to increasing the current velocity inside the inlet which slows the closure of the inlet rather than parallel ones.

The accumulation of sediments inside the inlet in the case of parallel jetty resulted from a strong eddy vortex formation at the inner part of the inlet as shown in Fig. 11b. In general, results identify that combined eastern jetty of length $360 \mathrm{~m}$ with inclined western one of $800 \mathrm{~m}$ will contribute in enhancing the stabilizing Rosetta promontory but the inlet will require to be dredged annually. It is also recommended that dredged materials could be placed in the critical spot that 
experience erosion as shown in Fig. 11a to protect seawall from failure if the foundation are exposed.

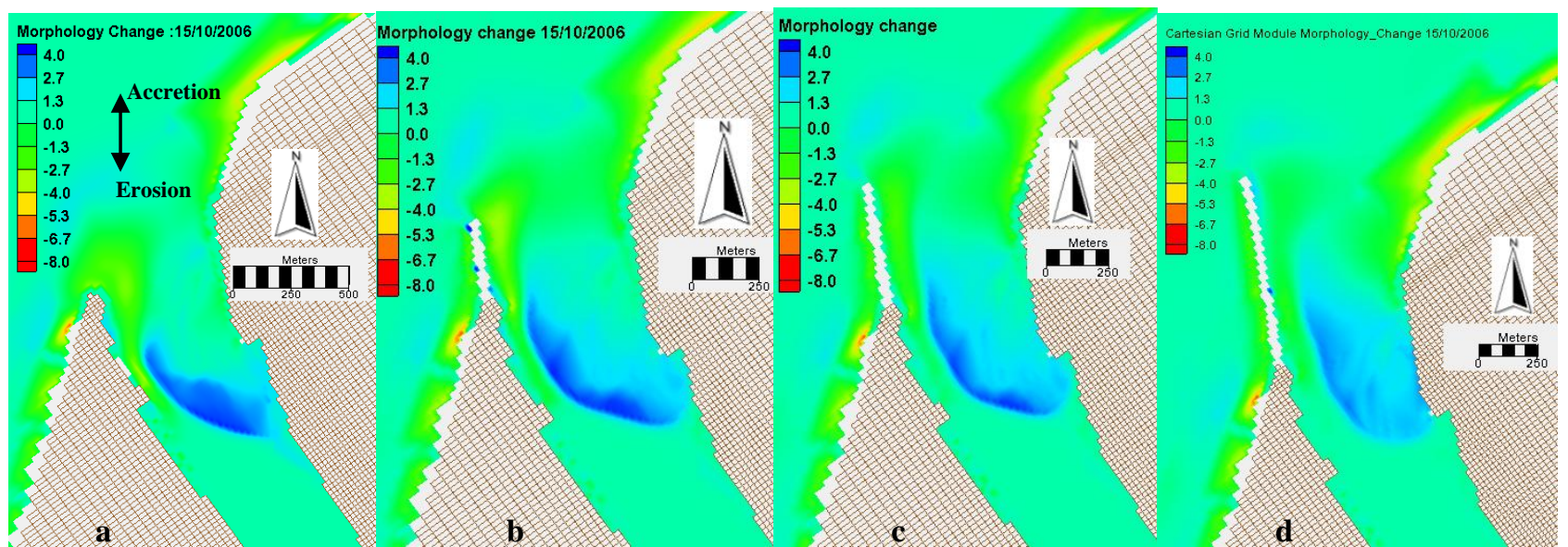

Fig. 6. Model results of the morphological changes on Rosetta Promontory due to using western jetties after one year. a) no action case, b) jetty length $300 \mathrm{~m}$, c) jetty length $500 \mathrm{~m}$, d) jetty length $800 \mathrm{~m}$.

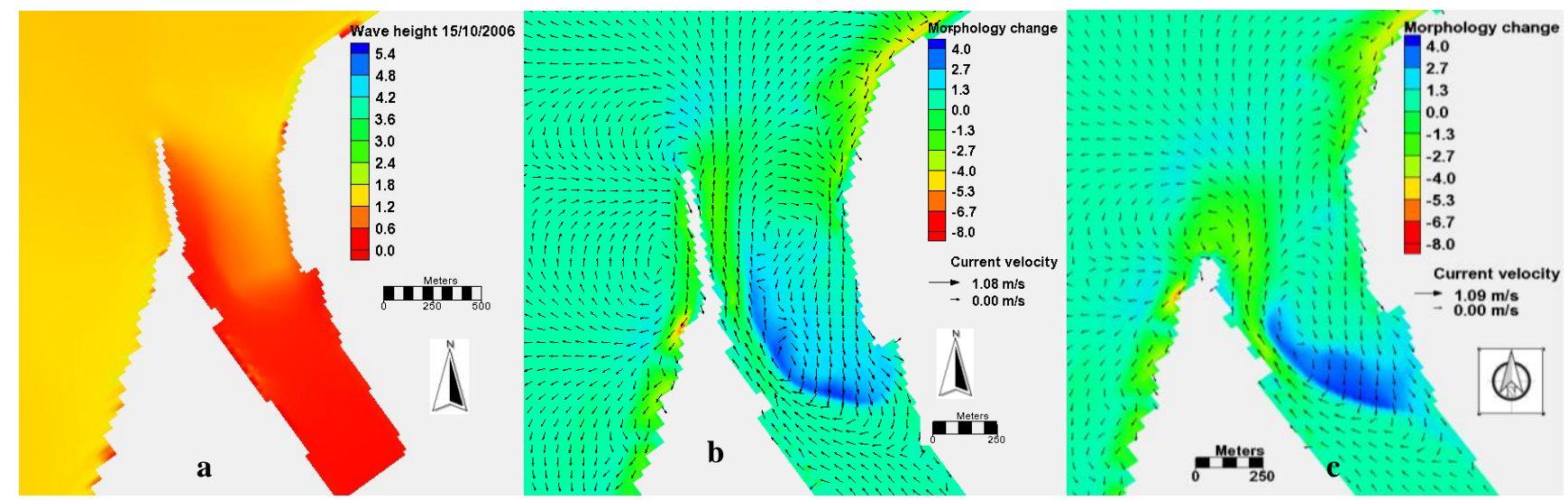

Fig. 7. a) Wave distribution around the jetty of $500 \mathrm{~m}$ length, b) Current distribution around the jetty of $500 \mathrm{~m}$ length, c) Current distribution in case of no action.
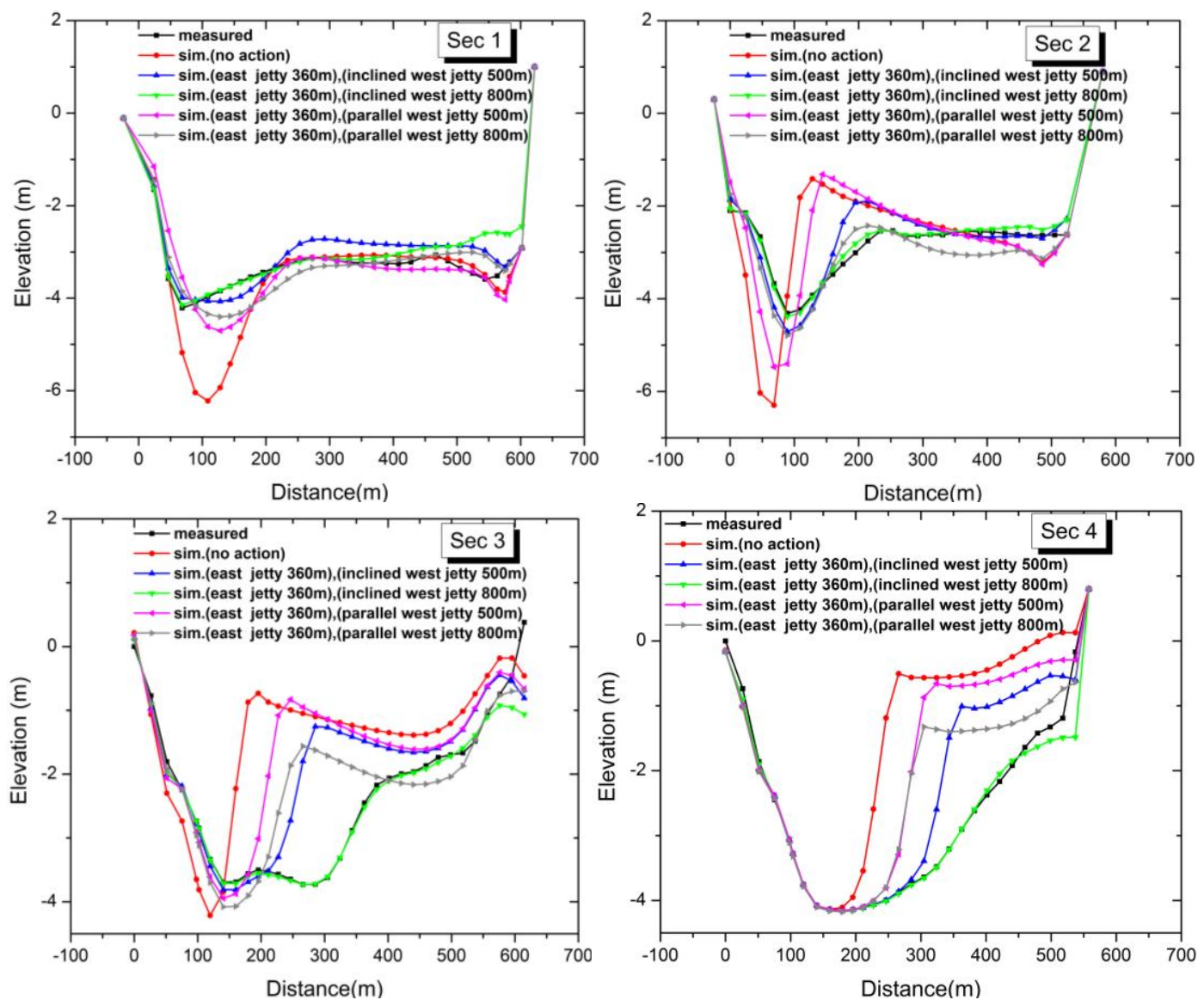

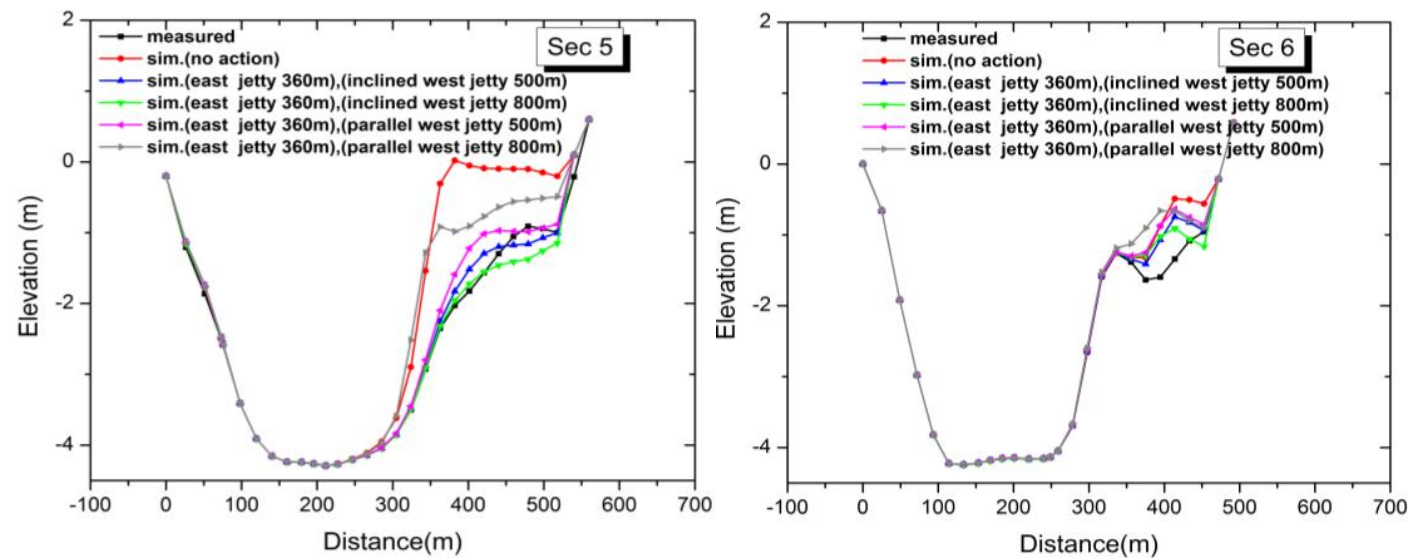

Fig. 8. The effect of the different scenarios on the bed level at different cross sections inside the inlet after one year.

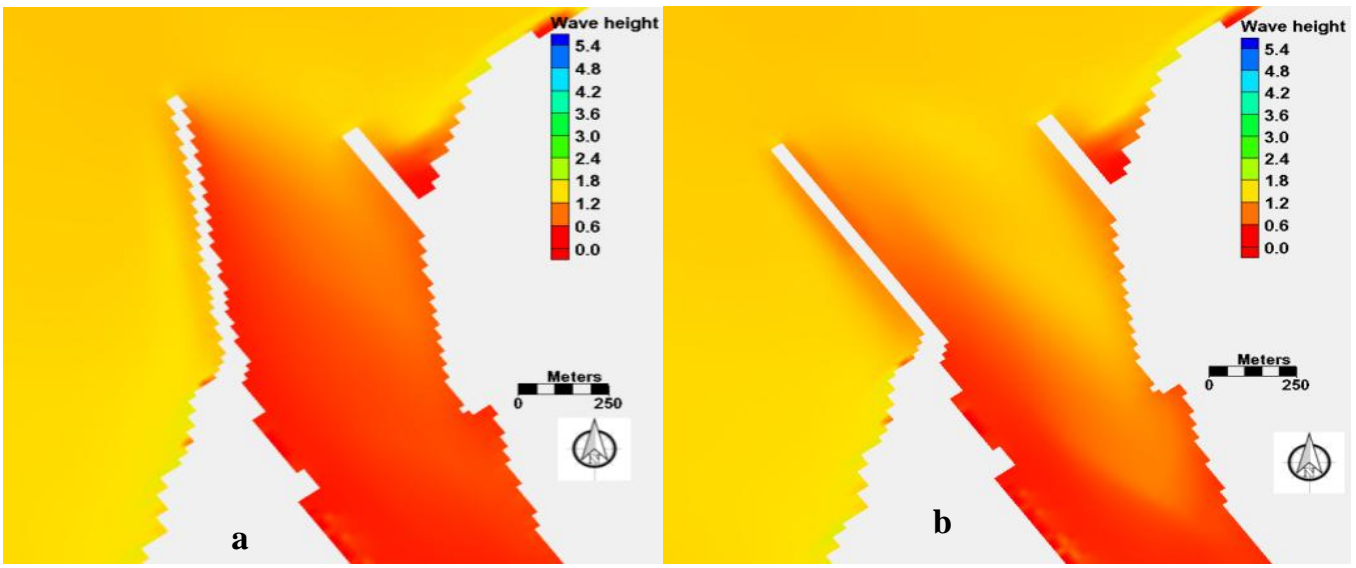

Fig. 9. a) Wave distribution around the eastern jetty of $360 \mathrm{~m}$ length with inclined western one of length $800 \mathrm{~m}$, b) Wave distribution around the eastern jetty of $360 \mathrm{~m}$ length with parallel western one of length $800 \mathrm{~m}$.

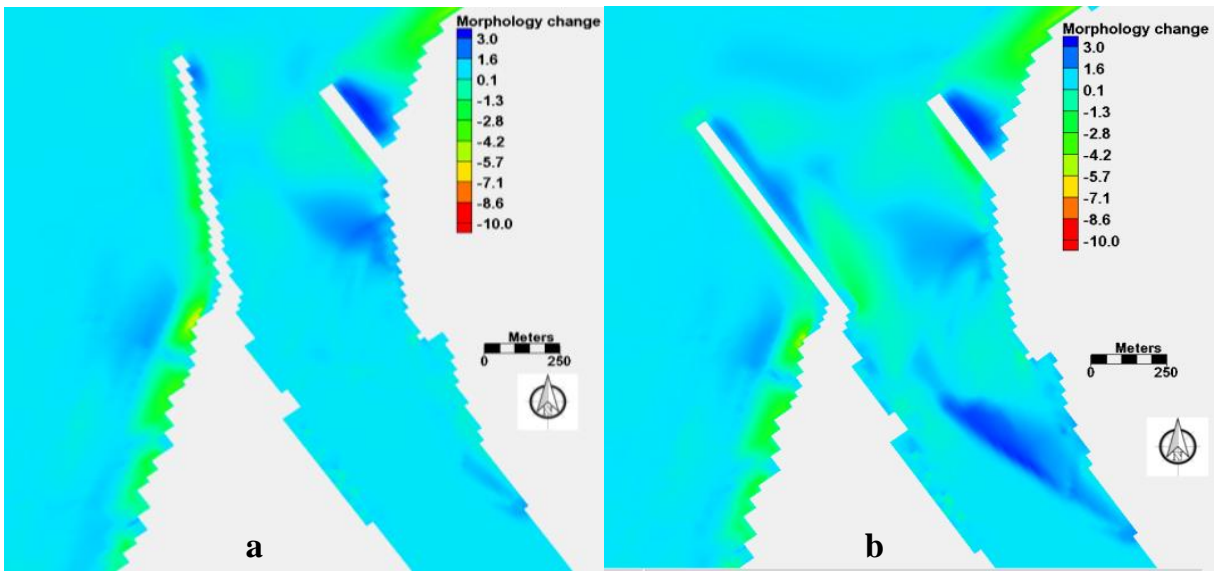

Fig. 10. Model results of morphological changes of Rosetta Promontory after one year, a) eastern jetty of length $360 \mathrm{~m}$ with inclined western one of $800 \mathrm{~m}$ length, b) eastern jetty of length $360 \mathrm{~m}$ with parallel western one of $800 \mathrm{~m}$ length.

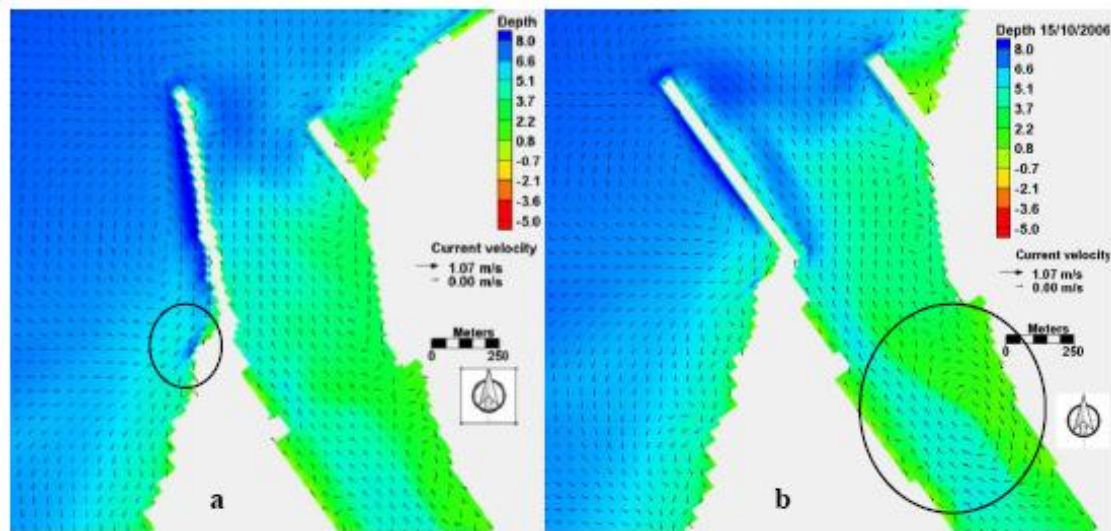

Fig. 11. Model results of grid depths of Rosetta Promontory after one year with current velocity vectors, a) eastern jetty of length $360 \mathrm{~m}$ with inclined western one of $800 \mathrm{~m}$ length, b) eastern jetty of length $360 \mathrm{~m}$ with parallel western one of $800 \mathrm{~m}$ length. 


\section{CONCLUSION}

Rosetta promontory suffers from many coastal problems as erosion problem along the coastline and accretion problem inside the inlet. Two groups of scenarios are proposed as an attempt to overcome the problem. The main idea is to reach a new condition of stability for the Rosetta Promontory by using coastal measures. These coastal structures are used to control the coastal hydrodynamics and sediment movement within the estuary.

The first group was used to test western jetty with different lengths resulting in reduction of the wave heights inside the inlet that affect generated currents. The second group consists of the best solution in the first group combined with an eastern jetty resulting in a reduction in the current induced sediments as the nodal point at the eastern revetment divert the current into the estuary.

CMS two dimension numerical model is used to check the effectiveness of these scenarios. All scenarios were simulated for one year.

It was found that the western jetties of lengths $500,800 \mathrm{~m}$ for the first group have a better effect on the stability of the inlet than others. From the comparison between the (eastern jetty combined with the inclined western one), and (eastern jetty combined with the parallel western one), it was found that the inclined jetty has better results than other as it decreases the sediment accumulation inside the inlet due to the shifting of wave breaking outside the inlet. Particularly, combined eastern jetty of length $360 \mathrm{~m}$ with inclined western one of $800 \mathrm{~m}$ helped in stabilizing the Rosetta promontory. Also it is recommended to dredge the inlet annually, and pumping the sediments in the critical areas that suffer from erosion in front of seawalls till a sustainable solution is reached.

\section{ACKNOWLEDGMENT}

Ali Masria would like to thank Egyptian Ministry of Higher Education (MoHE) for granting him the $\mathrm{PhD}$ scholarships. Also, thanks and appreciation are due to Egypt-Japan University of Science and Technology (E-JUST) for their support and for offering the tools needed for this research. Corps of Engineers for his great and continuous technical support. This work was partially supported by JSPS "Core-to-Core Program, B.Asia-Africa Science Platforms". Also, he would like to thank all. Thanks for my dear Eng. Lihwa Lin, Research Hydraulic Engineer, at Coastal and Hydraulics Laboratory, US Army Corps of Engineers for his great and continuous technical support.

\section{REFERENCES}

[1] N. T. Lam, M. J. F. Stive, H. J. Verhagen, and Z. B. Wang, "Morphodynamics of hue tidal inlets, Vietnam," in Proc. Asian and Pacific Coasts, 2007, pp. 692-705.

[2] A. C. Horrevoets, H. H. G. Savenije, J. N. Schuurman, and S. Graas, "The influence of river discharge on tidal damping in alluvial estuaries," Journal of Hydrology, vol. 294, pp. 213-228, 2004.

[3] D. M. FitzGerald, "Geomorphic variability and morphologic and sedimentologic controls on tidal inlets," Journal of Coastal Research, pp. 47-71, 1996.

[4] A. Vila-Concejo, Ó. Ferreira, B. D. Morris, A. Matias, and J. M. A Dias, "Lessons from inlet relocation: examples from Southern Portugal," Coastal Engineering, vol. 51, no. 10, pp. 967-990, 2004.

[5] B. Pass, P. Wang, and T. M. Beck, "Morphodynamics of an anthropogenically altered dual-inlet system: John's pass and blind pass, west-central Florida, USA," Marine Geology, vol. 291-294, pp. 162-175, 2012.

[6] W. V. Leussen and J. Dronkers, "Physical processes in estuaries: An introduction," Physical Processes in Estuaries, Springer, 1988, pp. $1-18$.

[7] P. Bruun and F. Gerritsen, "Stability of coastal inlets," Coastal Engineering Proceedings, vol. 1, no. 7, p. 23, 1960.

[8] D. M. FitzGerald, "Shoreline erosional-depositional processes associated with tidal inlets," Hydrodynamics and sediment Dynamics of Tidal Inlets, Springer, 1988, pp. 186-225.

[9] J. Murtagh and H. Nelson, "Narrabeen lagoon entrance sand fluidisation scheme pilot study," in Proc. 11th Australasian Conference on Coastal and Ocean Engineering: Coastal Engineering a Partnership with Nature; Preprints of Papers, 1993, p. 609.

[10] J. A. G. Cooper, "Sedimentary processes in the river-dominated Mvoti estuary, South Africa," Geomorphology, vol. 9, no. 4, pp. 271-300, 1994.

[11] L. C. Van Rijn, "Estuarine and coastal sedimentation problems," International Journal of Sediment Research, vol. 20, no. 1, pp. 39-51, 2005.

[12] D. M. FitzGerald, N. C. Kraus, and E. B. Hands, Natural Mechanisms of Sediment bypassing at Tidal Inlets, US Army Corps of Engineers Vicksburg, MS, 2000.

[13] N. C. Kraus, L. Lin, E. R. Smith, D. J. Heilman, and R. C. Thomas, "Long-term structural solution for the mouth of Colorado River Navigation Channel, Texas," Engineer Research and Development Centre, 2008.

[14] W. P. Beach, K. J. Connell, and G. A. Zarillo, "Model Evaluation of Shoaling and Morphologic Response to Storms at Moriches Inlet, Long Island, New York," Journal of Coastal Research, pp. 76-85, 2011.

[15] A. S. M. Ahmed, "Numerical Model as a Tool to Investigate Coastsl Problems in Egypt," in Proc. Tenth International Water Technology Conference, IWTC10, 2006, pp. 933-944.

[16] O. E. Frihy, "The necessity of environmental impact assessment (EIA) in implementing coastal projects: lessons learned from the Egyptian Mediterranean Coast," Ocean \& Coastal Management, vol. 44, no. 7-8, pp. 489-516, Jan. 2001.

[17] W. R. El Sayed, M. A. Ali, M. M. Iskander, and M. Fanos, "Evolution of Rosetta Promontory during the Last 500 Years, Nile Delta Coast, Egypt," in Proc. the Eight International Conference on the Mediterranean Coastal Environment, Alexandria, Egypt, 2007, vol. 1.

[18] S. A. J. Douglas and L. Inman, "The nile littoral cell and man's impact on the coastal zone of the southeastern mediterranean," in Proc. the International Conference on Coastal Engineering, no. 19, pp. $1600-1617,1984$

[19] O. Frihy and K. Dewidar, "Patterns of erosion/sedimentation, heavy mineral concentration and grain size to interpret boundaries of littoral sub-cells of the Nile Delta, Egypt," Marine Geology, vol. 199, no. 1-2, pp. 27-43, Aug. 2003.

[20] A. S. M. Ahmed, "Mathematical model investigation of the suitable countermeasure for the erosion problem at Rosetta Promontory, Egypt," in Proc. the Sixth International Summer Symposium, JSCE, Saitama University, 2004, no. 1991, pp. 157-160.

[21] A. Masria, M. M. Iskander, A. A. Negm, and O. Saavedra, "Numerica simulation of constructing jetties to Stabilize Rosetta Inlet, Egypt," in Proc. Seventeenth International Water Technology Conference, IWTC17 Istanbul., 2013.

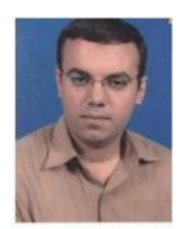

Ali Masria was born in 1982 at Dakahliya, Egypt. He has got his bachelor of science degree in civil engineering, Faculty of Engineering, Mansoura University, Mansoura in 2006. Ali's master degree of science was in irrigation and hydraulic engineering from Irrigation and Hydraulics Dept., Faculty of Engineering, Mansoura University, Mansoura in 2010. Now, he is a PhD student at E-JUST. He worked as a demonstrator at the Irrigation and Hydraulic Engineering Department, Faculty of Engineering, Mansoura University, Mansoura, Egypt from 2006 to 2010. From 2010 till now, he has been an assistant lecturer at the Irrigation and Hydraulic Engineering Department, Faculty of Engineering, Mansoura University, Mansoura, Egypt.

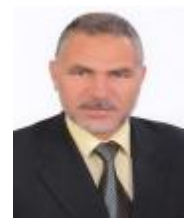

Abdelazim Negm was born in Sharkia, Egypt. His background is civil engineering because he was graduated from Irrigation and Environmental Engineering Dept. in 1985. Prof. Negm has got his M.Sc. degree from Ain Shams University in 1990 in hydrology of the nile basin. He got the PhD degree in 1990 in hydraulics.

Currently, he is a professor of water resources in 
Egypt-Japan University for Science and Technology (E-JUST) since Oct. 2012 and chairman of the Environmental Engineering Dept. at E-JUST since Feb. 17, 2013. He worked as a demonstrator in Faculty of Engineering, Zagazig University in 1986 and continued till he occupied the position of vice dean for Academic and Student Affair. He was promoted as a professor of hydraulics. His research areas are wide to include hydraulic, hydrology and water resources. He published about 200 papers in national and international journals and conferences. He is listed in (a) Marquis Who is Who?, (b) IBC's 2000 Outstanding Intellectuals of the 21st Century, and (c) ABI directory for his achievement in the field of Hydraulics and Water Resources. He participated in more than 55 conferences. He has awarded the prizes of best papers three times. He participates in the two EU funded international projects. For his detailed information one can visit his websites www.amneg.name.eg and www.amnegm.com.

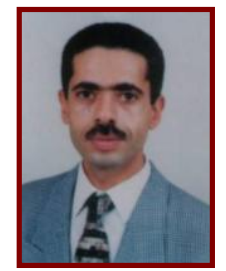

Moheb M. Iskander is an associated professor, head of Hydrodynamic Department, Coastal Research Institute, National Water Research Center, Alexandria, Egypt. He has got his B.Sc. degree in civil engineering in 1993 and $\mathrm{PhD}$ degree in 2005 in coastal engineering from Alexandria University. He has the following professional experience: Sharing in many of the CoRI projects in studying coastal processes, some field activities, proposing problem solving by using mathematical models, coastal structure designing and participating in reports writing Modified 2D numerical model (ImSedTran-2D model) for wave distribution and coastal sediment transport with a special module for coral reef from 2002 to 2005 .

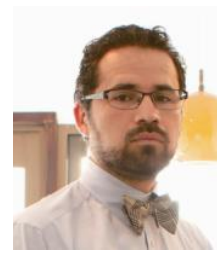

Oliver C. Saavedra is a $\mathrm{PhD}$ in civil engineering (applied hydrology oriented). $\mathrm{He}$ is an associate professor at Tokyo Institute of Technology and for adjunct professor to E-JUST since January 2010 to present. He has four years teaching experience in advanced hydrology, GIS, water resources management lectures at graduate school. His major research interests are in development of decision supporting tools for water resources management including optimal dam operation, flood control. He has about three years' experience as a researcher (hydrology and WRM) and two years' experience as a consultant engineer (water supply, sanitation, infrastructure) and two years' experience as a hydraulic engineer (water distribution systems). His project coordinator is "Integrated Water Resources and Environmental Management for Asian and African Mega-delta under Climate Change Effects". 